
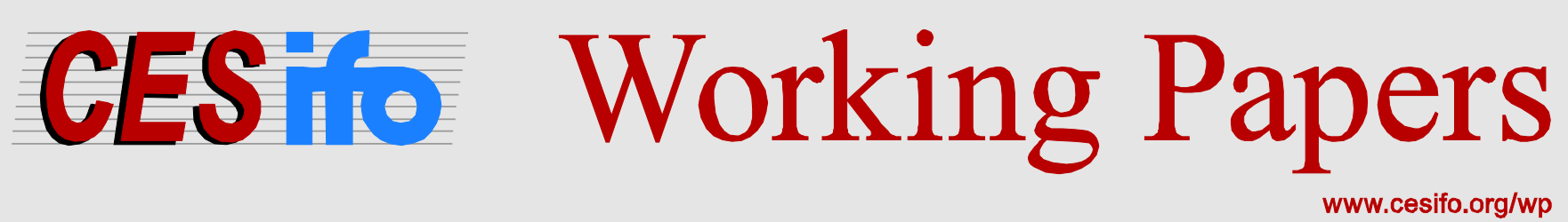

\title{
On the Implications of Introducing Cross-Border Loss-Offset in the European Union
}

\author{
Zarko Kalamov \\ Marco Runkel
}

CESIFO WORKING PAPER NO. 5436

CATEgORY 1: PUBLIC FINANCE

JULY 2015

An electronic version of the paper may be downloaded

- from the SSRN website:

- from the RePEc website:

- from the CESifo website:

wWw.SSRN.com

www.RePEc.org

www.CESifo-group.org/wp 


\title{
On the Implications of Introducing Cross-Border Loss-Offset in the European Union
}

\begin{abstract}
This article investigates a tax competition model where countries compete for capital and profits of multinational enterprises (MNEs) through statutory tax rates and cross-border loss-offset provisions, which allow a transfer of foreign subsidiaries' losses to the parent company. A joint implementation of full cross-border loss-relief is welfare maximizing, because it ensures production efficiency and no profit shifting in equilibrium. Local governments choose zero level of the loss-relief in a noncooperative equilibrium, if only capital is mobile and relax the lossoffset, when MNEs engage in profit shifting. Therefore, allowing multinationals to undertake international tax planning activities may be welfare-improving in our model.
\end{abstract}

JEL-Code: H320, F230.

Keywords: cross-border loss-offset, tax competition, profit shifting.

Zarko Kalamov

School of Economics and Management University of Technology Berlin

Straße des 17 Juni 135

Berlin / Germany

zarko.y.kalamov@tu-berlin.de
Marco Runkel

School of Economics and Management University of Technology Berlin

Straße des 17 Juni 135

Berlin / Germany

marco.runkel@tu-berlin.de

July 14, 2015 


\section{Introduction}

The current system of taxation of multinational enterprises (MNEs) in the European Union is Separate Accounting, where profits are taxed in the country where the multinational declares them. The European Commission has proposed a joint augmentation of this Separate Accounting system by a cross-border loss-offset under which losses of foreign subsidiaries of multinational firms reduce taxable profits of this firm's headquarter in another country. Such a common loss-offset provision should be first step toward the implementation of a common consolidated corporate tax base (CCCTB) where multinationals' taxable profits (and losses) are first consolidated and then allocated back to the member countries for tax purposes according to a certain apportionment formula that reflects the relative economic activities in the member states (European Commission, 2006a). While the public finance literature has analyzed thoroughly the welfare consequences of a move from Separate Accounting to the CCCTB, it has largely neglected the implications of a move toward Separate Accounting with cross-border loss-relief.

Furthermore, a unilateral introduction of cross-border loss compensation, where only single countries grant loss-offset provisions but others do not, is rarely observed in reality. Only four countries in the EU allow multinational firms to reduce domestic tax liabilities using losses of foreign subsidiaries: Austria, Denmark, France and Italy (European Commission, 2006a).

This article views the cross-border loss-offset as a tax competition instrument. We show that countries, that compete with other countries for both mobile capital and profits of MNEs, grant general loss-offset provisions. However, countries which compete only for real investment find it optimal to prohibit the loss compensation. Thus, we provide an argument that may help explain the diverse behavior of member states of the European Union. Additionally, we show that a joint introduction of a loss-offset mechanism, in the way proposed by the European Commission, eliminates the distortions arising from the current tax code and is welfare-improving.

The paper analyzes a model of $n$ symmetric countries, each of which hosts a MNE with subsidiaries in all countries. MNEs may shift profits from one country to another. Local governments set corporate tax rates and the degree of cross-border loss-offset in order to attract investment and profits from each MNE. The cross-border scheme allows a parent company to use foreign subsidiary's losses to reduce its tax liability, but no transfer of losses in the opposite direction is permitted. This is the mechanism supported by the European Parliament (European Parliament, 2008) 1

This paper is the only one, to our knowledge, that investigates the endogenous choice of the degree of cross-border loss-offset in a tax competition setting. The main contribution of the article is in deriving the conditions under which local governments choose to allow for a cross-border transfer of losses. Furthermore, we show that a coordinated increase of the loss compensation is welfare-improving.

We obtain three main results. First, from the viewpoint of a social planner, it is optimal to allow

\footnotetext{
${ }^{1}$ The mechanism is called "deduction/reintegration method", because once the foreign subsidiary becomes profitable, the home government recaptures the loss-relief. The purpose is to avoid a double use of losses. We have left away this characteristic of the mechanism, because it is not essential to the results.
} 
for full loss-offset. The rationale for this policy is that currently domestic subsidiaries are allowed to pool their profits and losses which, in the absence of cross border loss-offset, creates a differential treatment of domestic and foreign subsidiaries by the countries' tax codes $2^{2}$ This differential treatment stimulates (i) domestic investment (thus creating production inefficiency) and (ii) shifting of profits abroad (because these profits may not be taxed there due to the higher probability of incurring losses). By introducing cross-boder loss-offset, the social planner ensures that domestic and foreign subsidiaries are treated identically by the tax code. Thus, there is production efficiency in equilibrium and no profit shifting occurs.

Second, we find that investment in foreign subsidiaries increases with more generous cross-border loss-relief, because the transfer of losses raises the expected return on foreign investment. Therefore, unilateral introduction of the loss-offset exerts a positive externality on the other countries. The increased foreign capital demand raises the interest rate and lowers domestic investment. As a result, a positive loss-offset rule reduces domestic tax revenues both directly (through the losses transferred by the MNE) and indirectly (through lower domestic investment). Therefore, if only capital is mobile, the loss relief is not employed in the decentralized equilibrium. Third, allowing for profit shifting in the decentralized economy, we find that the amount of profits an MNE shifts from the parent company to foreign subsidiaries falls when the cross-border loss relief is relaxed, because of the possibility to shift losses in the opposite direction. This is a counteracting negative externality, which increases the equilibrium loss-offset above zero. Therefore, we find that allowing for profit shifting activities of multinational firms reduces the gap between the first-best and the decentralized loss-relief and can be welfare-improving. To the best of the authors' knowledge, Hong and Smart (2010) is the only other article to derive a utility enhancing role for profit shifting. They find that international tax planning reduces the tax rate sensitivity of investment, which increases equilibrium tax rates.

Our analysis is related to two strands of literature. The first investigates the introduction of crossborder loss transfer in the European Union. The second deals with the implications of tax asymmetries for investment and profit shifting behavior.

The literature on cross-border loss-relief is relatively scarce. Gérard and Weiner (2003) and Gérard (2005) study tax competition in a setting with an exogenously given degree of symmetric loss-offset provisions. They find that the ability to transfer losses mitigates competition in statutory tax rates. However, in contrast to our analysis they do not derive the first-best or the equilibrium decentralized levels of loss-relief.

The closest to our article is the paper of Haufler and Mardan (2014), who analyze the effect of an introduction of cross-border loss-offset on the equilibrium tax rates, when countries compete for real investment. They find that tax competition is intensified, if governments base the tax rebate for foreign subsidiaries' losses on its own tax rate. On the other hand, if the loss-relief is based on the tax rate of the

\footnotetext{
${ }^{2}$ In 2006, domestic loss relief within a group of companies (parent and subsidiary) was available in 18 EU countries. However, only 4 Member States allow for loss-offset between a domestic parent and a foreign subsidiary(European Commission $2006 \mathrm{~b})$.
} 
country in which the foreign subsidiary resides, then tax competition is mitigated by a relaxation of the loss-relief. Similar to Gérard and Weiner (2003) and Gérard (2005), Haufler and Mardan (2014) do not consider the optimal loss-offset provision from the viewpoints of a social planner and local governments. This is the main topic of our analysis.

Niemann and Treisch (2005) investigate the impact of the "deduction/reintegration method", which was introduced in Austria in 2005, on MNEs' investment decisions. They find that real investment in the foreign subsidiary is in general favored by loss-offsets, unless the parent does not have enough profit to absorb foreign losses. Nevertheless, they neglect the welfare implications of loss compensation and also treat the loss-offset provision as exogenously given.

The literature on tax asymmetries focuses mostly on asymmetric treatment of profits and losses of a single firm 3 . The current article contributes to the literature by analyzing an asymmetry in the treatment of losses of domestic and foreign subsidiaries. We find that it favors domestic investment and reporting of profits abroad and, thus, leads to distortions in the world allocation of capital and profits.

Creedy and Gemmell (2011) investigate asymmetric treatment of own profits and losses, when firms engage in loss shifting in order to minimize their tax payments. They show that higher asymmetry discourages loss shifting, i.e. it reduces the behavioral effect on tax revenues following tax rate hikes. Our model predicts that profit shifting is lower under a lower asymmetry in the treatment of home and foreign losses, i.e. when the parent is able to use a greater proportion of foreign losses to lower its tax liability. The reason is that loss shifting to the parent company is a substitute from transferring profits abroad.

The rest of the paper is organized as follows. Section 2 describes the model and derives the firm behavior. As a benchmark Section 3 investigates the Pareto efficient corporate tax rate and loss-relief. Section 4 determines the degree of cross-border loss-offset in a decentralized setting. Section 5 simulates the model. Section 6 discusses the policy implications for the EU and Section 7 concludes.

\section{The Model}

We consider a tax competition model with $n$ countries, indexed by $i, j, l=1, \ldots, n$. Country $i$ hosts a MNE that we denote by $\mathrm{MNE}_{i}$ and that has subsidiaries in all jurisdictions $j=1, \ldots, n$. Additionally, country $i$ is populated by a single resident, who is assumed to be risk neutral.

$\mathrm{MNE}_{i}$ invests capital $k_{i}^{j}$ in country $j$ with total capital demand of $\mathrm{MNE}_{i}$ denoted by $k_{i}=\sum_{j} k_{i}^{j}$. The per unit cost of capital is deterministic and given by $r>0$. All MNEs produce a homogeneous consumption good. Production of the subsidiary of $\mathrm{MNE}_{i}$ located in country $j$ is $y_{i}^{j}$ and is determined by the production function $f\left(k_{i}^{j}\right)$ with positive but decreasing marginal returns, i.e. $f^{\prime}>0>f^{\prime \prime}$. Furthermore, we assume that the production function is quadratic such that $f\left(k_{i}^{j}\right)=\left(a-(b / 2) k_{i}^{j}\right) k_{i}^{j}$,

\footnotetext{
${ }^{3}$ The implications of tax asymmetries for investment are investigated by Auerbach (1986); Mayer (1986); Devereux (1989); Altshuler and Auerbach (1990). Panteghini 2001b a analyzes neutrality of asymmetric tax functions. More recently, Edgerton (2010) estimates investment responses to tax incentives in a setting with tax carrybacks and carryforwards.
} 
where $a, b>0$. In order to discuss the role of cross-border loss-offset provisions, we have to take into account the possibility that foreign subsidiaries of a MNE incur losses. We do this by assuming that the production of $\mathrm{MNE}_{i}$ 's foreign subsidiary in country $j$ is subject to a multiplicative country specific shock $\theta_{i}^{j}$, i.e.

$$
y_{i}^{j}=\theta_{i}^{j} f\left(k_{i}^{j}\right), \quad \forall i \neq j,
$$

where $\theta_{i}^{j}, \forall i \neq j$ are i.i.d. random variables. The shock equals $1 / p$ with probability $\left.p, p \in\right] 0,1[$ and 0 with probability $1-p$. This specification ensures that if $\mathrm{MNE}_{i}$ invests equal amounts at home and at some foreign subsidiary, the expected product is the same, i.e. $E\left(\theta_{i}^{j}\right)=1$. However, due to the uncertainty of foreign investment, the MNE may experience a loss abroad. In order to focus on cross-border loss-offset we assume that domestic production is deterministic, i.e. $y_{i}^{i}=f\left(k_{i}^{i}\right)$.

$\mathrm{MNE}_{i}$ is able to shift profits between its headquarter and foreign subsidiaries. We denote by $s_{i}^{j}>0$ the profits of $\mathrm{MNE}_{i}$ shifted from its subsidiary in country $j$ to some other subsidiary or the headquarter in country $i$. If $s_{i}^{j}<0$, then profits are shifted to the subsidiary in country $j$. Since profits transferred away from one subsidiary must appear in the tax base of another subsidiary, we impose the condition $\sum_{j} s_{i}^{j}=0$. Moreover, profit shifting is associated with quadratic concealment $\operatorname{costs} C\left(s_{i}^{1}, \ldots, s_{i}^{n}\right)=$ $(c / 2) \sum_{j} s_{i}^{j 2}, c>0$, which are assumed to be identical for all MNE: 4

The government in country $i$ taxes the profits of all subsidiaries operating in country $i$ at a rate $t_{i}$. If a subsidiary is profitable, its tax base is $y_{i}^{j}-\rho r k_{i}^{j}-s_{i}^{j}$, where $\rho \in[0,1]$ denotes the rate of allowance of capital cost, assumed to be ideantical across countries5 If it experiences a loss, it does not pay taxes. Additionally, the local government in country $i$ allows $\mathrm{MNE}_{i}$ to use its foreign losses to reduce domestic tax liabilities. The rate at which losses can be transferred is $\sigma_{i} \in[0,1]$, where $\sigma_{i}=0$ denotes the case of no loss-offset and $\sigma_{i}=1$ represents the case of a full cross-border loss-relief 6 . Thus, the ex-post worldwide tax liability of $\mathrm{MNE}_{i}$ is given by

$$
\Pi_{i t}=t_{i}\left(f\left(k_{i}^{i}\right)-\rho r k_{i}^{i}-s_{i}^{i}\right)-t_{i} \sigma_{i} \sum_{\substack{j=1 \\ j \neq i}}^{n}\left(\rho r k_{i}^{j}+s_{i}^{j}\right) \mathbb{1}_{\left\{\theta_{i}^{j}=0\right\}}+\sum_{\substack{j=1 \\ j \neq i}}^{n} t_{j}\left(\frac{1}{p} f\left(k_{i}^{j}\right)-\rho r k_{i}^{j}-s_{i}^{j}\right) \mathbb{1}_{\left\{\theta_{i}^{j}=\frac{1}{p}\right\}},
$$

\footnotetext{
${ }^{4}$ Modelling the optimal international tax planning decision with concealment costs is usual in the literature (see e.g. Haufler and Schjelderup (2000); Haufler and Runkel (2012); Hong and Smart (2010)). For an alternative approach according to which benefits of profit shifting are set against expected fines from the government see Devereux et al. (2008).

${ }^{5}$ Without loss of generality, we assume that concealment costs are not deductible from the tax base.

${ }^{6}$ Austria allows a proportion of losses equal to the ownership share of the parent in the foreign company to be transferred. We model the degree of offset provisions in a different way in order to focus on its implications for investment and tax planning activities. The effects of cross-border loss-offset on the ownership structure of multinational enterprises are irrelevant for our purposes.

${ }^{7}$ We make two assumptions in defining $\Pi_{i t}$ this way. First, it is assumed that $s_{i}^{j}$ is not too negative, such that $-\left(\rho r k_{i}^{j}+\right.$ $\left.s_{i}^{j}\right)<0$, i.e. if a negative shock occurs at a foreign subsidiary, it will actually experience a loss. Otherwise, the cross-border loss-offset will never be used. It can be shown that this assumption is satisfied in equilibrium if concealment costs are sufficiently high (i.e. $c$ is large). Second, we assume that even under full loss-relief $\left(\sigma_{i}=1\right)$ and occurrence of negative shocks in all foreign jurisdictions, the sum of foreign losses and home capital cost allowances is less than output at home, i.e. $f\left(k_{i}^{i}\right)-\rho r k_{i}>0$.
} 
where $\mathbb{1}_{\{A\}}$ is the indicator function and equals 1 if $A$ holds and 0 if $A$ does not hold. The first term in Equation (2) represents the tax payments of the headquarter of $\mathrm{MNE}_{i}$, the second term denotes all tax rebates for losses incurred by the foreign subsidiaries of $\mathrm{MNE}_{i}$, while the last term gives the tax payments of these foreign subsidiaries in countries $j \neq i$ when they are profitable. Ex-post profits of $\mathrm{MNE}_{i}$ can then be written as

$$
\Pi_{i}=f\left(k_{i}^{i}\right)+\sum_{\substack{j=1 \\ j \neq i}}^{n} \theta_{i}^{j} f\left(k_{i}^{j}\right)-\Pi_{i t}-r k_{i}-C,
$$

where we used the condition $\sum_{j} s_{i}^{j}=0$ in order to cancel the profit shifting terms.

The multinational companies are assumed to make optimal investment and profit shifting decisions to maximize the firm value before the realization of productivity shocks. While the assumption that investment is undertaken before the value of $\theta_{i}^{j}$ is known is common in the literature, the assumption of an ex-ante profit shifting choice needs more elaboration. Once the uncertainty is unveiled, the MNE may wish to adjust the values of $s_{i}^{j}$. Nevertheless, profit shifting may also be irreversible. This is the case, for example, if the transfer of profits occurs through interest payments on internal debt, as the proportion of internal financing must be chosen simultaneously with the investment decision. It may also be the case, if the MNE shifts profits through manipulation of transfer prices. If the subsidiaries trade inputs, these transactions occur before production takes place and must also be priced ex-ante. Since the tax authorities check whether the transfer prices meet the arm's length principle by comparing them to comparable transactions from independent firms, sudden changes of transfer prices ex-post may be associated with concealment costs which surpass the potential tax savings.

Investors are assumed to be risk-neutral and value maximization is thus identical to maximization of expected firm profit: 8 Therefore, $\mathrm{MNE}_{i}$ solves the following problem:

$$
\begin{aligned}
\max _{\left\{k_{i}^{j}, s_{i}^{j}\right\}_{j=1}^{n}} E\left(\Pi_{i}\right)= & f\left(k_{i}^{i}\right)\left(1-t_{i}\right)+t_{i}\left(\rho r k_{i}^{i}+s_{i}^{i}\right)+t_{i} \sigma_{i} \sum_{\substack{j=1 \\
j \neq i}}^{n}\left[\rho r k_{i}^{j}+s_{i}^{j}\right](1-p) \\
& +\sum_{\substack{j=1 \\
j \neq i}}^{n}\left[f\left(k_{i}^{j}\right)\left(1-t_{j}\right)+t_{j} p\left(\rho r k_{i}^{j}+s_{i}^{j}\right)\right]-r k_{i}-C \text { s.t. } \sum_{j=1}^{n} s_{i}^{j}=0 .
\end{aligned}
$$

The Lagrange function of (4) depends on $2 n+1$ variables $\left(\left\{k_{i}^{j}, s_{i}^{j}\right\}_{j=1}^{n}\right.$ and the Lagrange multiplier). The solution of the above maximization problem is presented in detail in Appendix A and gives the following

\footnotetext{
${ }^{8}$ The assumption that expected profit maximization is identical to value maximization is usual in the tax competition literature. Wildasin and Wilson (1998) and Lee (2004) employ this simplification by assuming that investors are able to shed all risk from firm ownership by owning only identical shares of foreign firms (households do not own the home firm in their models, because its profits are positively correlated with wage income).
} 
results:

$$
\begin{aligned}
f^{\prime}\left(k_{i}^{i}\right) & =\frac{1-\rho t_{i}}{1-t_{i}} r \\
f^{\prime}\left(k_{i}^{j}\right) & =\frac{1-\rho\left(t_{j} p+t_{i} \sigma_{i}(1-p)\right)}{1-t_{j}} r, \quad j=1, \ldots, n, j \neq i, \\
s_{i}^{i} & =\frac{t_{i}\left(1-\sigma_{i}(1-p)\right)(n-1) / n-p \sum_{j \neq i} t_{j} / n}{c}, \\
s_{i}^{j} & =\frac{p\left(t_{j}-\sum_{l \neq i} t_{l} / n\right)-t_{i}\left(1-\sigma_{i}(1-p)\right) / n}{c}, \quad j=1, \ldots, n, j \neq i .
\end{aligned}
$$

The above equations show that even in a symmetric situation with $t_{i}=t_{j}=t$ and $\sigma_{i}=\sigma_{j}=\sigma$, as long as $\sigma<1$, the firm will (i) invest more at home than abroad $\left(f^{\prime}\left(k_{i}^{i}\right)<f^{\prime}\left(k_{i}^{j}\right)\right.$ from (5a) and (5b) and (ii) shift profits abroad $\left(s_{i}^{i}>0\right.$ from $(5 \mathrm{c})$ and $s_{i}^{j}<0$ from $(5 \mathrm{~d})$ ). The reason for the first result is that investment at home has a higher expected return. If a foreign subsidiary of the MNE experiences a loss, it will not be fully taxed. On the other hand, the home subsidiary can always use a proportion $\rho$ of capital costs to reduce its tax liability. This leads to production inefficiency, which is greater, the lower the cross-border loss-offset is. If and only if $\sigma_{i}=1$, is the marginal product of investment and, thus, investment itself, in the home and foreign subsidiaries equalized in a symmetric situation.

However, the offset provision has an impact on profit shifting, which goes in the opposite direction. The expected benefits of reporting profits abroad are increased, when losses cannot be transferred fully to the parent $(\sigma<1)$. In the absence of cross-border loss-offset $(\sigma=0)$, the expected benefits of shifting one Euro of profits from the parent to the subsidiary in country $j$ are $t_{i}-p t_{j}$, which is positive in a symmetric situation? On the other hand, when $\sigma_{i}=1$, then multinationals do not have incentives to report home profits in the foreign subsidiaries. The reason is that, in the case of full loss-offset $(\sigma=1)$, transferring profits abroad leads to an equal reduction of the amount of losses, which can then be offset against the home tax liability.

The first-order conditions (5a)- $5 \mathrm{~b}$ ) determine the capital demand in each country. Assuming that the household in country $i$ is endowed with an exogenous amount of capital $\bar{k}_{i}$, the capital market clearing condition becomes $\sum_{i} \bar{k}_{i}=\sum_{i} \sum_{j} k_{i}^{j}$. Together the first-order conditions and the capital market clearing condition determine the capital allocations $\left\{k_{i}^{j}\right\}_{i, j=1}^{n}$ and the interest rate $r$ as functions of the policy parameters $\left\{t_{i}, \sigma_{i}\right\}_{i=1}^{n}$. Totally differentiating these equations and evaluating the resulting expressions at a symmetric situation with $t_{i}=t, \sigma_{i}=\sigma$, we derive the following comparative static effects with respect

\footnotetext{
${ }^{9}$ We again assume that profits shifted are less than the loss experienced abroad. This simplification is not important for the result, while it helps to explain the intuition more clearly.
} 
to $t_{i}$ (full derivation is presented in Appendix B) 10

$$
\begin{aligned}
\frac{\partial r}{\partial t_{i}} & =-\frac{\left(f^{\prime}\left(k_{i}^{i}\right)-\rho r\right)+(n-1)\left(f^{\prime}\left(k_{i}^{j}\right)-\rho r(p+\sigma(1-p))\right)}{n[(1-\rho t)+(n-1)(1-\rho t(p+\sigma(1-p)))]}<0, \\
\frac{\partial k_{i}^{i}}{\partial t_{i}} & =-\frac{(n-1)\left[f^{\prime}\left(k_{i}^{j}\right) n(1-\rho)-f^{\prime}\left(k_{i}^{i}\right) \rho(1-p)(1-\sigma)\right]}{n b(1-t)[(1-\rho t)+(n-1)(1-\rho t(p+\sigma(1-p)))]}, \\
\frac{\partial k_{i}^{j}}{\partial t_{i}} & =-\frac{(1-\rho t(p+\sigma(1-p)))}{b(1-t)} \frac{\partial r}{\partial t_{i}}+\frac{r \rho \sigma(1-p)}{b(1-t)}>0, \quad \forall j \neq i, \\
\frac{\partial k_{j}^{j}}{\partial t_{i}} & =-\frac{(1-\rho t)}{b(1-t)} \frac{\partial r}{\partial t_{i}}>0, \quad \forall j \neq i, \\
\frac{\partial k_{j}^{l}}{\partial t_{i}} & =-\frac{(1-\rho t(p+\sigma(1-p)))}{b(1-t)} \frac{\partial r}{\partial t_{i}}>0, \quad \forall j, l ; j \neq l, j \neq i, l \neq i, \quad \Gamma \\
\frac{\partial k_{j}^{i}}{\partial t_{i}} & =-\frac{\Gamma}{n b(1-t)^{2}[(1-\rho t)+(n-1)(1-\rho t(p+\sigma(1-p)))]}<0, \quad \forall j \neq i,
\end{aligned}
$$

where

$$
\begin{aligned}
\Gamma \equiv & r(n-1)(1-\rho t(p+\sigma(1-p)))[1-\rho+(n-1)(1-\rho(p+\sigma(1-p))) \\
& +n \rho \sigma(1-p)(1-t)]+r n \rho(1-t)(1-p-\rho t \sigma(1-p))>0 .
\end{aligned}
$$

All of the above comparative static results are unambiguous except for the effect of $t_{i}$ on the home investment of $\mathrm{MNE}_{i}$, given by (6b). While an increase in the tax rate raises the cost of capital of the home subsidiary, it also lowers the interest rate $r$ according to (6a). If $\sigma<1$, the second effect may dominate and $\partial k_{i}^{i} / \partial t_{i}$ may be positive. However, looking at $6 \mathrm{~b}$ and noting that $f^{\prime}\left(k_{i}^{j}\right) \geq f^{\prime}\left(k_{i}^{i}\right)$, a sufficient condition for $\partial k_{i}^{i} / \partial t_{i}<0$ to hold is $\rho \leq n /(n+(1-p)(1-\sigma))$. This condition is satisfied if (i) the number of countries is large (large $n$ ), (ii) the degree of uncertainty is low (large $p$ ) or (iii) the degree of loss-offset is large (large $\sigma$ ). Even if none of the above conditions holds, the deductible fraction of capital cost $\rho$ may be low enough such that $\partial k_{i}^{i} / \partial t_{i}<0$. For example, if $n=10, p=0.5$ and there is no loss-offset, i.e. $\sigma=0$, the sufficient condition for $\partial k_{i}^{i} / \partial t_{i}<0$ implies $\rho \leq 0.95$. Furthermore, the negative effect of $t_{i}$ on the interest rate $r$ and its positive impact on the expected tax rebate for $\mathrm{MNE}_{i}$ 's foreign subsidiaries' losses raises $k_{i}^{j}$ according to [6c. Moreover, 6f] shows that $t_{i}$ lowers the foreign direct investment in country $i k_{j}^{i}$, due to its positive effect on the cost of capital of these subsidiaries. Lastly, the depressed interest rate stimulates investment elsewhere according to (6d) and (6e).

Second, the comparative static results with respect to $\sigma_{i}$, evaluated at a symmetric situation, are

\footnotetext{
${ }^{10}$ Note that in a symmetric situation each MNE invests the same amount in the home subsidiary $k_{i}^{i}=k_{j}^{j}$ and undertakes identical investments in its foreign subsidiaries $k_{i}^{j}=k_{i}^{l}, \forall l, j \neq i$. Nevertheless, $k_{i}^{i} \neq k_{i}^{j} \Leftrightarrow \sigma<1$.
} 
derived in Appendix B and are given by

$$
\begin{aligned}
& \frac{\partial r}{\partial \sigma_{i}}=\frac{r \rho t(1-p)(n-1)}{n[(1-\rho t)+(n-1)(1-\rho t(p+\sigma(1-p)))]}>0, \\
& \frac{\partial k_{i}^{i}}{\partial \sigma_{i}}=\frac{\partial k_{j}^{j}}{\partial \sigma_{i}}=-\frac{(1-\rho t)}{b(1-t)} \frac{\partial r}{\partial \sigma_{i}}<0, \\
& \frac{\partial k_{j}^{i}}{\partial \sigma_{i}}=\frac{\partial k_{j}^{l}}{\partial \sigma_{i}}=-\frac{(1-\rho t(p+\sigma(1-p)))}{b(1-t)} \frac{\partial r}{\partial \sigma_{i}}<0, \quad \forall j, l \neq i, j \neq l, \\
& \frac{\partial k_{i}^{j}}{\partial \sigma_{i}}=\frac{r \rho t(1-p)\left[n(1-\rho t)+(n-1)^{2}(1-\rho t(p+\sigma(1-p)))\right]}{b(1-t) n[(1-\rho t)+(n-1)(1-\rho t(p+\sigma(1-p)))]}>0, \quad \forall j \neq i .
\end{aligned}
$$

A relaxation of the cross-border loss-offset lowers the $\mathrm{MNE}_{i}$ 's cost of capital of investing abroad. This effect raises investment $k_{i}^{j}$ according to $7 \mathrm{~d}$ and, therefore, has a positive impact on the interest rate $r$ (given by (7a)). Due to the increase in the interest rate, all remaining capital allocations decline according to $(7 \mathrm{~b})$ and $(7 \mathrm{c})$.

Additionally, the effects of the policy instuments on profit shifting can be derived from $5 \mathrm{cc}-(5 \mathrm{~d})$. Noting that (5c) and (5d) depend only on $s_{i}^{i}$ and $s_{i}^{j}$, respectively, one can differentiate each equation with respect to $t_{i}$ and immediately derive the following comparative statics effects of a change in the tax rate in country $i$ :

$$
\begin{aligned}
& \frac{\partial s_{i}^{i}}{\partial t_{i}}=\frac{(n-1)\left(1-\sigma_{i}(1-p)\right)}{n c}>0, \\
& \frac{\partial s_{j}^{j}}{\partial t_{i}}=-\frac{p}{n c}<0, \quad \forall j \neq i, \\
& \frac{\partial s_{i}^{j}}{\partial t_{i}}=-\frac{\left(1-\sigma_{i}(1-p)\right)}{n c}<0, \quad \forall j \neq i, \\
& \frac{\partial s_{j}^{i}}{\partial t_{i}}=\frac{(n-1) p}{n c}>0, \quad \forall j \neq i, \\
& \frac{\partial s_{l}^{j}}{\partial t_{i}}=-\frac{p}{n c}<0, \quad \forall j, l \neq i, j \neq l .
\end{aligned}
$$

An increase in the tax rate in country $i$ lowers the profits reported in $i$, i.e. $s_{i}^{i}$ and $s_{j}^{i}$ rise according to $8 \mathrm{a}$ and $8 \mathrm{~d}$. On the other hand, the profits reported by the subsidiaries in all other jurisdictions go up, i.e. $s_{j}^{j}, s_{i}^{j}$ and $s_{l}^{j}$ decrease due to the higher tax differentials $t_{i}-t_{j}, \forall j \neq i$.

Lastly, the effects of the loss-offset provisions on profit shifting can also be derived by differentiating 5 (5c) and (5d) with respect to $\sigma_{i}$. The resulting expressions are:

$$
\begin{aligned}
\frac{\partial s_{i}^{i}}{\partial \sigma_{i}} & =-\frac{(n-1) t_{i}(1-p)}{n c}<0, \\
\frac{\partial s_{i}^{j}}{\partial \sigma_{i}} & =\frac{t_{i}(1-p)}{n c}>0, \quad \forall j \neq i, \\
\frac{\partial s_{j}^{j}}{\partial \sigma_{i}}=\frac{\partial s_{j}^{i}}{\partial \sigma_{i}}= & \frac{\partial s_{l}^{j}}{\partial \sigma_{i}}=0, \quad \forall j, l \neq i, l \neq j .
\end{aligned}
$$

Loss-offset provisions increase the $\mathrm{MNE}_{i}$ 's incentives to report losses abroad, which in case of a negative shock can be deducted from the domestic tax base. Therefore, $s_{i}^{i}$ declines and $s_{i}^{j}$ increases according to 
9a) and 9b), respectively. Since the loss-offset rule $\sigma_{i}$ applies only to the multinational with headquarter in country $i$, it has no impact on the incentives of other multinationals to transfer profits as shown in (9c).

The household in country $i$ is endowed with a fixed amount of capital $\bar{k}_{i}$ and $1 / n \%$ ownership share of each firm 11 . It consumes a quantity $x_{i}$ of the consumption good. As it does not face a saving decision, consumption equals income, which consists of net return to the capital endowment $\bar{k}_{i}$ and a proportion of the profits of all multinationals according to its ownership share:

$$
x_{i}=r \bar{k}_{i}+\frac{1}{n} \sum_{j=1}^{n} \Pi_{j} .
$$

Additionally, each government collects tax revenue from the subsidiaries of all MNEs operating in its country and uses it to provide a public good to its resident. Public consumption $g_{i}$ is given by

$$
g_{i}=t_{i}\left(f\left(k_{i}^{i}\right)-\rho r k_{i}^{i}-s_{i}^{i}\right)-t_{i} \sigma_{i} \sum_{\substack{j=1 \\ j \neq i}}^{n}\left(\rho r k_{i}^{j}+s_{i}^{j}\right) \mathbb{1}_{\left\{\theta_{i}^{j}=0\right\}}+t_{i} \sum_{\substack{j=1 \\ j \neq i}}^{n}\left(\frac{1}{p} f\left(k_{j}^{i}\right)-\rho r k_{j}^{i}-s_{j}^{i}\right) \mathbb{1}_{\left\{\theta_{j}^{i}=\frac{1}{p}\right\}}
$$

Furthermore, we assume that the marginal rate of substitution between private and public consumption is constant and equal to one, i.e. expected utility is the sum of the expected consumption of the private and public goods:

$$
E\left(U_{i}\right)=E\left(x_{i}+g_{i}\right) .
$$

The above utility function has been chosen in order to abstract from the issue of the optimal provision of public goods ${ }^{12}$ The reason for choosing the functional form given in 12 is that it allows a clear identification of the mechanisms, which lead to the need for coordinated increase of the cross-border loss-offset, as well as the externalities, which determine the choice of $\sigma_{i}$ in a noncooperative game13. Additionally, each local government takes into consideration the sensitivity of its tax base with respect to $t_{i}$ and $\sigma_{i}$, which is described by equations (5a) - 9c). Before considering the equilibrium local government policies, we derive the optimal social planner's choice as a benchmark.

\section{Social Planner's Choice}

In this section we assume that there is a social planner, who chooses the efficient levels of the tax rates and of the cross-border loss-offset of each country. Thus, the central planner maximizes over $t_{i}$ and $\sigma_{i}, i=1, \ldots, n$, the sum of expected utilities of the residents of all countries, given by

$$
E(U)=\sum_{i=1}^{n} E\left(U_{i}\right)
$$

\footnotetext{
${ }^{11}$ For simplicity, we do not explicitly model the optimal ownership decisions of households.

${ }^{12}$ In $12, g_{i}$ can be interpreted as a transfer from the government to the citizen of country $i$.

${ }^{13}$ In section 6 we discuss the implications of introducing a more general utility function.
} 
The first-order condition of 13 with respect to the degree of loss-offset is

$$
\begin{aligned}
& \frac{\partial E(U)}{\partial \sigma_{i}}=t_{i} \sum_{j \neq i}\left(\rho r k_{i}^{j}+s_{i}^{j}\right)(1-p)(1-1)+\sum_{j=1}^{n} \frac{\partial E\left(U_{j}\right)}{\partial r} \frac{\partial r}{\partial \sigma_{i}} \\
&+\sum_{j=1}^{n} t_{j}\left[\left(f^{\prime}\left(k_{j}^{j}\right)-\rho r\right) \frac{\partial k_{j}^{j}}{\partial \sigma_{i}}+\sum_{i \neq j}\left(\left(f^{\prime}\left(k_{i}^{j}\right)-p \rho r\right) \frac{\partial k_{i}^{j}}{\partial \sigma_{i}}-\sigma_{j} \rho r(1-p) \frac{\partial k_{j}^{i}}{\partial \sigma_{i}}\right)\right] \\
&-t_{i} \frac{\partial s_{i}^{i}}{\partial \sigma_{i}}-\sum_{\substack{j=1 \\
j \neq i}}^{n}\left[t_{j} p+t_{i} \sigma_{i}(1-p)\right] \frac{\partial s_{i}^{j}}{\partial \sigma_{i}}=0,
\end{aligned}
$$

where

$$
\begin{aligned}
\frac{\partial E\left(U_{j}\right)}{\partial r}= & \left(\bar{k}_{j}-\frac{1}{n} \sum_{i=1}^{n} k_{i}\right)+\frac{1}{n} \sum_{i=1}^{n}\left[t_{i} \rho k_{i}^{i}+\sum_{l \neq i} \rho k_{i}^{l}\left(t_{i} \sigma_{i}(1-p)+t_{l} p\right)\right] \\
& -\left[t_{j} \rho k_{j}^{j}+\sum_{i \neq j}\left(t_{j} \sigma_{j} \rho k_{j}^{i}(1-p)+t_{j} p \rho k_{i}^{j}\right)\right] .
\end{aligned}
$$

The rationale of (14) is as follows. An increase in the degree of loss-offset in country $i, \sigma_{i}$, reduces directly government $i$ 's tax base by the same amount by which it increases private income. Since the marginal rate of substitution is one, the overall direct welfare effect is zero (captured by the first term in (14)). The second term on the first row of Equation (14) determines the impact on welfare through its effect on the cost of capital $r$. It is expanded in 15 and consists of three terms, whose sum equals zero in a symmetric optimum. The first term in 15 is zero when $\bar{k}_{i}=k_{i}, \forall i$. The second and third terms represent the effect of $r$ on the MNEs' tax payments and government revenues, respectively. They are of opposite signs and cancel each other out under symmetry. There are two remaining terms in 14: the terms on the second (third) row of (14) show the welfare implications of the reactions of investment (profit shifting) to changes in the loss compensation. In a symmetric optimum with $t_{i}=t_{j}=t$ and $\sigma_{i}=\sigma_{j}=\sigma$, both terms are positive whenever $\sigma<1$. We prove this by inserting Equations (7a)-(7d) and $9 \mathrm{a}$ - $-9 \mathrm{~b})$ in the above first-order condition. Evaluating at a symmetric optimum, we get

$$
\frac{\partial E(U)}{\partial \sigma_{i}}=t(p-1)(1-\sigma) \frac{\partial s_{i}^{i}}{\partial \sigma_{i}}+\frac{\operatorname{trn}(1-\rho t) \rho(1-p)(1-\sigma)}{b(1-t)^{2}} \frac{\partial r}{\partial \sigma_{i}}=0 .
$$

The above equation is zero only at $\sigma=1$, which means that a full cross-border loss-offset is joint-welfare maximizing. The reason is that it ensures production efficiency and zero profit shifting at the optimum. 
The first-order condition with respect to $t_{i}$ is given by

$$
\begin{array}{r}
\frac{\partial E(U)}{\partial t_{i}}=\left[\left(f\left(k_{i}^{i}\right)-\rho r k_{i}^{i}-s_{i}^{i}\right)+\sum_{j \neq i}\left(\left(f\left(k_{j}^{i}\right)-p\left(\rho r k_{j}^{i}+s_{j}^{i}\right)\right)-\sigma_{i}(1-p)\left(\rho r k_{i}^{j}+s_{i}^{j}\right)\right)\right](1-1) \\
+\sum_{j=1}^{n} \frac{\partial E\left(U_{j}\right)}{\partial r} \frac{\partial r}{\partial t_{i}}+\sum_{j=1}^{n} t_{j}\left\{-\frac{\partial s_{j}^{j}}{\partial t_{i}}-p \sum_{i \neq j} \frac{\partial s_{i}^{j}}{\partial t_{i}}-\sigma_{j}(1-p) \sum_{i \neq j} \frac{\partial s_{j}^{i}}{\partial t_{i}}\right. \\
\left.+\left(f^{\prime}\left(k_{j}^{j}\right)-\rho r\right) \frac{\partial k_{j}^{j}}{\partial t_{i}}+\sum_{i \neq j}\left(\left(f^{\prime}\left(k_{i}^{j}\right)-p \rho r\right) \frac{\partial k_{i}^{j}}{\partial t_{i}}-\sigma_{j} \rho r(1-p) \frac{\partial k_{j}^{i}}{\partial t_{i}}\right)\right\}=0 .
\end{array}
$$

As in the first-order condition with respect to $\sigma_{i}$, the direct effect of $t_{i}$ on welfare vanishes, because it raises tax revenues and lowers private income by the same amount (first term in (16)). Second, its impact on the interest rate also vanishes in a symmetric optimum as in (14). The indirect effects of $t_{i}$ on tax revenues in all countries through changes in investment and profit shifting are displayed in curvy brackets in Equation (16) and determine the optimal tax rate. Using Equations (6a)- (6f) and 8a - 8e , the above first-order condition can be simplified in a symmetric optimum to

$$
\frac{\partial E(U)}{\partial t_{i}}=-\frac{t(n-1)[\rho r(1-p)(1-\sigma)]^{2}}{b(1-t)^{2}[(1-\rho t)+(n-1)(1-\rho t(p+\sigma(1-p)))]}-\frac{(n-1) t(1-p)^{2}(1-\sigma)^{2}}{n c}=0 .
$$

The above equation is negative in the case of $\sigma<1$ and identically equal to zero for any tax rate if $\sigma=1$. The reason is that at less than full loss-offset, corporate income taxation leads to production inefficiency and profit shifting to foreign subsidiaries. Therefore, zero taxes are optimal in this case. However, above we show that the Pareto efficient loss-offset is $\sigma=1$. Consquently, the inefficiencies disappear and there is no role for the corporate tax. As a result, the social planner is indifferent between all possible tax rates $t_{i} \in[0,1[$. Therefore, denoting the Pareto efficient variables in the symmetric case as $\hat{\sigma}$ and $\hat{t}$, we have

$$
\hat{\sigma}=1, \quad \hat{t} \in[0,1[.
$$

In the rest of the analysis we will anylize the equilibrium noncoordinated levels of $t_{i}$ and $\sigma_{i}$ and consider the welfare implications of a coordinated increase in the loss provisions only. This is also the focus of the European Commission, which aims at introducing cross-border loss-offset throughout the European Union, while leaving the tax rate decisions to local governments (European Commission, 2006a).

\section{Tax Competition}

Turning to a tax competition environment, we assume that governments choose their tax rates and lossoffset provisions simultaneously and non-cooperatively. An example where such a decentralized choice has happened is the Austrian tax reform in 2005. It reduced the corporate tax rate from $34 \%$ to $25 \%$ and introduced the possibility to transfer foreign losses to an Austrian parent at a proportion equal to the ownership share in the foreign subsidiary. 
Thus, country $i$ maximizes utility of its resident, given by (12), over $t_{i}$ and $\sigma_{i}$, taking $t_{j}, \sigma_{j}, j \neq i$ as given and expecting the firms' behavioral responses to its policy as described by equations (5a) - 9c). The resulting first-order conditions are

$$
\begin{aligned}
& \frac{\partial E\left(U_{i}\right)}{\partial \sigma_{i}}= t_{i} \sum_{j \neq i}\left(\rho r k_{i}^{j}+s_{i}^{j}\right)(1-p)\left(\frac{1}{n}-1\right)+\frac{\partial E\left(U_{i}\right)}{\partial r} \frac{\partial r}{\partial \sigma_{i}}-t_{i}\left(1-\sigma_{i}(1-p)\right) \frac{\partial s_{i}^{i}}{\partial \sigma_{i}} \\
&+t_{i}\left[\left(f^{\prime}\left(k_{i}^{i}\right)-\rho r\right) \frac{\partial k_{i}^{i}}{\partial \sigma_{i}}+\sum_{j \neq i}\left(\left(f^{\prime}\left(k_{j}^{i}\right)-p \rho r\right) \frac{\partial k_{j}^{i}}{\partial \sigma_{i}}-\sigma_{i} \rho r(1-p) \frac{\partial k_{i}^{j}}{\partial \sigma_{i}}\right)\right]=0 . \\
& \frac{\partial E\left(U_{i}\right)}{\partial t_{i}}= \frac{n-1}{n}\left[\left(f\left(k_{i}^{i}\right)-\rho r k_{i}^{i}-s_{i}^{i}\right)+\sum_{j \neq i}\left(\left(f\left(k_{j}^{i}\right)-p\left(\rho r k_{j}^{i}+s_{j}^{i}\right)\right)-\sigma_{i}(1-p)\left(\rho r k_{i}^{j}+s_{i}^{j}\right)\right)\right] \\
&+ \frac{\partial E\left(U_{i}\right)}{\partial r} \frac{\partial r}{\partial t_{i}}+t_{i}\left[\left(f^{\prime}\left(k_{i}^{i}\right)-\rho r\right) \frac{\partial k_{i}^{i}}{\partial t_{i}}+\sum_{j \neq i}\left[\left(f^{\prime}\left(k_{j}^{i}\right)-p \rho r\right) \frac{\partial k_{j}^{i}}{\partial t_{i}}-\sigma_{i} \rho r(1-p) \frac{\partial k_{i}^{j}}{\partial t_{i}}\right]\right. \\
&\left.-\left(1-\sigma_{i}(1-p)\right) \frac{\partial s_{i}^{i}}{\partial t_{i}}-p \sum_{j \neq i} \frac{\partial s_{j}^{i}}{\partial t_{i}}\right]=0 .
\end{aligned}
$$

In order to gain more intuition regarding the optimal tax rate and loss-offset provisions, proceed stepwise and consider two cases. In the first case, multinationals face infinitely high concealment costs of profit shifting such that $s_{i}^{j}=0, \forall i, j$, i.e. there is no profit shifting and countries compete only for physical capital. This case leads to easily interpretable equilibrium results. In the second case, both investment and profits are mobile, which is the general situation considered in 18 and 19 above.

It has to be noted that, irrespective of the degree of profit shifting, the social planner's optimal policy remains the same. This can be directly inferred from (17), which states that $\hat{\sigma}$ and $\hat{t}$ are independent of the marginal concealment $\operatorname{costs} c$. Thus, there is no need to re-define the Pareto efficient levels of $t$ and $\sigma$ for each case and we can judge the efficiency of the noncooperative policies by comparing them to (17).

\subsection{Competition for Real Investment}

In this subsection, we consider a situation, in which $s_{i}^{j}=0$ and $\partial s_{i}^{j} / \partial z_{j}=0, z=t, \sigma, \forall i, j$. Thus, countries compete only for investment. The first-order conditions 18 and 19 become

$$
\begin{aligned}
\frac{\partial E\left(U_{i}\right)}{\partial \sigma_{i}}= & -t_{i} \sum_{j \neq i} \rho r k_{i}^{j}(1-p)\left(\frac{n-1}{n}\right)+t_{i}\left(f^{\prime}\left(k_{i}^{i}\right)-\rho r\right) \frac{\partial k_{i}^{i}}{\partial \sigma_{i}} \\
& +t_{i} \sum_{j \neq i}\left[\left(f^{\prime}\left(k_{j}^{i}\right)-p \rho r\right) \frac{\partial k_{j}^{i}}{\partial \sigma_{i}}-\sigma_{i} \rho r(1-p) \frac{\partial k_{i}^{j}}{\partial \sigma_{i}}\right]<0, \\
\frac{\partial E\left(U_{i}\right)}{\partial t_{i}}= & \frac{n-1}{n}\left[\left(f\left(k_{i}^{i}\right)-\rho r k_{i}^{i}\right)+\sum_{j \neq i}\left(f\left(k_{j}^{i}\right)-p \rho r k_{j}^{i}\right)-\sum_{j \neq i} \sigma_{i} \rho r k_{i}^{j}(1-p)\right] \\
& +t_{i}\left(f^{\prime}\left(k_{i}^{i}\right)-\rho r\right) \frac{\partial k_{i}^{i}}{\partial t_{i}}+t_{i} \sum_{j \neq i}\left[\left(f^{\prime}\left(k_{j}^{i}\right)-p \rho r\right) \frac{\partial k_{j}^{i}}{\partial t_{i}}-\sigma_{i} \rho r(1-p) \frac{\partial k_{i}^{j}}{\partial t_{i}}\right]=0 .
\end{aligned}
$$


Equation 201 represents the first-order condition with respect to $\sigma_{i}$ and is always negative. In order to understand this, we consider the fiscal externalities of $\sigma_{i}$, i.e. the effect of $\sigma_{i}$ on welfare in another country $j \neq i$. There are two positive externalities of the loss-relief. They are given by

$$
\begin{aligned}
\mathrm{PE}_{\sigma}= & \frac{n-1}{n} \sum_{j=1}^{n} \frac{\partial E\left(\Pi_{j}\right)}{\partial \sigma_{i}}=\frac{n-1}{n} t_{i} \sum_{j \neq i} \rho r k_{i}^{j}(1-p)>0, \\
\mathrm{CFE}_{\sigma}= & \sum_{j \neq i} \frac{\partial E\left(g_{j}\right)}{\partial \sigma_{i}}=\frac{t r}{b(1-t)^{2}} \frac{\partial r}{\partial \sigma_{i}}[(1-\rho t)(1-\rho+\rho n(1-p)(1-t \sigma)) \\
& +(n-1)(1-\rho t(p+\sigma(1-p)))(1-\rho(p+\sigma(1-p))+\rho n \sigma(1-p)(1-t))]>0 .
\end{aligned}
$$

First, due to the joint ownership of MNEs, a proportion $(n-1) / n$ of the change in expected profits accrues to the foreign residents. Since an increase in $\sigma_{i}$ raises the tax rebate for loss making subsidiaries, $\mathrm{MNE}_{i}$ 's profits go up. This effect defines a positive profit income externality $\mathrm{PE}_{\sigma}$ and is given by Equation 22, Second, higher loss compensation raises investment in the foreign subsidiaries of $\operatorname{MNE}_{i}\left(\partial k_{i}^{j} / \partial \sigma_{i}>0\right)$, which overcompensates its negative effect on investment undertaken by all other MNEs due to the increase in $r$. Thus, capital mobility leads to a second positive capital fiscal externality $\mathrm{CFE}_{\sigma}$, given by 23. As a result, the sum of externalities is positive and $\sigma_{i}$ is inefficiently low. Moreover, 20 contains three negative terms, which leads to zero loss-offset in equilibrium. The first term represents the direct effect of a relaxation of the loss-relief and is negative due to the $\mathrm{PE}_{\sigma}$, i.e. a higher level of $\sigma_{i}$ lowers tax revenues by more than it increases the income of the domestic household because of the international ownership of $\mathrm{MNE}_{i}$. The second term shows that tax revenues decline due to the negative impact of $\sigma_{i}$ on home investment of $\mathrm{MNE}_{i} k_{i}^{i}$. The last term also represents a negative effect on tax revenues through the lower inward foreign direct investment $\left(k_{j}^{i}\right.$ declines) and the higher base for tax rebates ( $k_{i}^{j}$ increases). Thus, 20 is negative and national governments do not have incentives to implement cross-border loss-offset.

The optimal tax rate is determined by inserting $\sigma_{i}=0$ in 21) and solving for $t_{i}$. The tax rate imposes two counteracting externalities on countries $j \neq i$. First, there is a negative profit income externality $\left(\mathrm{PE}_{t}\right)$, because a proportion $(n-1) / n$ of the burden of taxation is passed to the residents of countries $j \neq i$. Second, there is a positive fiscal externality $\left(\mathrm{CFE}_{t}\right)$, which stems from the augmenting effect that $t_{i}$ has on the tax bases in countries $j$. Evaluated at $\sigma_{i}=\sigma_{j}=0$, the externalities are given by

$$
\begin{aligned}
\mathrm{PE}_{t}(\sigma=0) & =-\frac{n-1}{n}\left[\left(f\left(k_{i}^{i}\right)-\rho r k_{i}^{i}\right)+\sum_{j \neq i}\left(f\left(k_{j}^{i}\right)-p \rho r k_{j}^{i}\right)\right]<0, \\
\mathrm{CFE}_{t}(\sigma=0) & =\frac{(n-1) t r}{(1-t)}\left[(1-\rho) \frac{\partial k_{j}^{j}}{\partial t_{i}}+(n-1)(1-\rho p) \frac{\partial k_{j}^{l}}{\partial t_{i}}\right]>0,
\end{aligned}
$$

where $\partial k_{j}^{j} / \partial t_{i}$ and $\partial k_{j}^{l} / \partial t_{i}$ are given by (6d) and 6e , respectively. Overall, the equilibrium tax rate is positive, which can be immediately seen by noting that (21) is positive at zero tax rates and zero lossoffset. Using a superscript * to denote a decentralized equilibrium with competition over real investment, we get

$$
\sigma^{*}=0, t^{*}>0 .
$$


A comparison of the above result and (17) shows that the equilibrium cross-border loss-offset is inefficiently low: $\sigma^{*}=0<\hat{\sigma}=1$. In order to determine whether $t^{*}$ is above or below the efficient tax rate, one needs to consider the first-order condition (16) of the social planner with respect to $t_{i}$ in the case of zero loss-offset. Plugging $\sigma_{i}=\sigma_{j}=0$ and $c \rightarrow \infty$ in (16), it becomes negative for all values of $t_{i}$. The reason is that in the absence of full loss-offset, each MNE invests more in the home subsidiary than abroad. This leads to production inefficiency, which is increasing in $t_{i}$. Therefore, it is optimal to set the tax rate at the lowest possible level $\hat{t}(\sigma=0, c \rightarrow \infty)=0$. Hence, the equilibrium decentralized tax rate is inefficiently high. Alternatively, one can prove that the corporate income tax is inefficiently high by showing that the sum of the externalities (24) and 25 is negative, when evaluated at $\sigma^{*}, t^{*}$.

$$
\mathrm{PE}_{t}+\mathrm{CFE}_{t}=-\frac{\operatorname{tr}^{2}(n-1)\left[\begin{array}{c}
(1-\rho p)(n-2)[(n-1)(1-\rho t p)+\rho(1-p)(1-\rho t)] \\
+2(\rho(1-p))^{2}(1-t)
\end{array}\right]}{b n(1-t)^{3}[1-\rho t+(n-1)(1-\rho t p)]}<0 .
$$

Nevertheless, a coordinated increase of the loss-relief to $\hat{\sigma}=1$ is always welfare-improving, irrespective of the inefficiency of $t^{*}$ or the change in $t^{*}$, following the reform. The reason lies in (17), which states that at the efficient loss-offset, any tax rate is welfare-maximizing. These results can be summarized in the following Proposition:

Proposition 1 When countries compete over real investment, the symmetric Nash equilibrium is characterized by an inefficiently low level of cross-border loss-offset provisions $\sigma^{*}=0<1=\hat{\sigma}$ and an inefficiently high tax rate $t^{*}>0=\hat{t}(\sigma=0, c \rightarrow \infty)$. A coordinated implementation of full cross-border loss-offset is welfare improving.

This result may explain why it is not a common practice to introduce cross-border loss-offsets. It is consistent with the policies of 24 of the 28 European Union member states, which do not allow for crossborder loss transfer. However, it cannot explain why the remaining four member states have relaxed the loss-offset provisions. This policy becomes optimal, if one considers mobility of profits, which is the next step in our analysis.

\subsection{Competition for Physical Capital and Profits}

In this subsection, we assume that both investment and profits are mobile. This means that the first-order conditions, which define the equilibrium levels of $t_{i}$ and $\sigma_{i}$, are (18) and (19). Even though no closed-form solution exists, we can describe the effects, which drive the equilibrium values of the choice variables. First, (18) shows that a unilateral increase of $\sigma_{i}$ affects welfare in country $i$ directly and through the reactions of investment and profit shifting. These three effects lead to three externalities on countries $j \neq i$. We have already considered the profit income externality $\left(\mathrm{PE}_{\sigma}\right)$ and the capital fiscal externality $\left(\mathrm{CFE}_{\sigma}\right)$. The sum of both externalities leads to zero equilibrium loss-relief $\sigma^{*}=0$ when only investment

\footnotetext{
${ }^{14} \mathrm{In}$ order to derive $\mathrm{PE}_{t}+\mathrm{CFE}_{t}$, we inserted the first-order condition 21 in 24.
} 
is mobile. When profits are mobile, a negative externality appears, which may shift the equilibrium loss compensation above zero. We call it the profit fiscal externality $\left(\mathrm{PFE}_{\sigma}\right)$ :

$$
\mathrm{PFE}_{\sigma}=\sum_{j \neq i} \sum_{l=1}^{n} \frac{\partial E\left(g_{j}\right)}{\partial s_{i}^{l}} \frac{\partial s_{i}^{l}}{\partial \sigma_{i}}=-\sum_{j \neq i} t_{j} p \frac{t_{i}(1-p)}{n c}<0 .
$$

The reason for the above negative externality is that the loss-relief gives an opportunity for "free" profit shifting, i.e. it allows MNEs to minimize their tax payments without having to incur the costs of tax planning. Therefore, the profits reported by the MNEs at the home subsidiary are increasing in the degree of the loss-offset. Equation (18) shows that, if the marginal costs of profit shifting $c$ are sufficiently small, the $\mathrm{PFE}_{\sigma}$ becomes strong enough to lead to a positive equilibrium loss-relief. This is the case if (??) is positive at $\sigma_{i}=0$, i.e. if

$$
\begin{aligned}
\left.\frac{\partial E\left(U_{i}\right)}{\partial \sigma_{i}}\right|_{\sigma_{i}=0}= & -\frac{n-1}{n} t_{i} \sum_{j \neq i}\left(\rho r k_{i}^{j}+s_{i}^{j}\right)(1-p) \\
& +t_{i}\left[\left(f^{\prime}\left(k_{i}^{i}\right)-\rho r\right) \frac{\partial k_{i}^{i}}{\partial \sigma_{i}}+\sum_{j \neq i}\left(f^{\prime}\left(k_{j}^{i}\right)-p \rho r\right) \frac{\partial k_{j}^{i}}{\partial \sigma_{i}}+\frac{(n-1) t_{i}(1-p)}{n c}\right]>0 .
\end{aligned}
$$

As a result, sufficiently strong profit shifting introduces an externality that counteracts the $\mathrm{PE}_{\sigma}$ and $\mathrm{CFE}_{\sigma}$ and may, thus, be welfare improving. If an interior solution of 18 exists, then the equilibrium loss-relief in the case of capital and profit mobility is between $\sigma^{*}=0$ and $\hat{\sigma}=1$.

On the other hand, (19) also shows that profit shifting has the expected negative impact on the equilibrium tax rate, because the profits reported by each MNE in country $i$ are declining in $t_{i}$. Since the tax rate is inefficiently high in the absence of profit shifting, this inefficiency seems to be mitigated. However, the tax rate is not necessarily lower when profits are mobile, because the increase in the equilibrium loss provision $\sigma$ has a positive impact on the tax bases and may lead to higher taxation. Overall it is not possible to analytically derive the sign of the change of the inefficiency in corporate taxation.

Nevertheless, a coordinated increase of the cross-border loss-offset to the efficient level $\hat{\sigma}=1$ is unambiguously welfare-improving, since at the efficient level, any local tax rate $t_{i}$ between zero and one is efficient. Denoting the equilibrium choice variables in case of mobile capital and profits as $\tilde{\sigma}$ and $\tilde{t}$, we can summarize our findings as follows.

Proposition 2 Under capital and profit mobility, the symmetric Nash equilibrium is characterized by less inefficient cross-border loss relief $\tilde{\sigma}>0=\sigma^{*}$. A coordinated implementation of full cross-border loss-offset is welfare improving.

The above result is able to elaborate on the anecdotal evidence for the reasons why countries relax crossborder loss-offset. For example, the Austrian government conducted its group tax reform in 2005 with the intention to make Austria an attractive destination for the establishment of holding companies (Niemann and Treisch, 2005). Even though we do not consider the firms' optimal headquarter location choice, we 
can use our framework to discuss how an MNE can benefit from moving its headquarter to a country with positive $\sigma$. If a multinational decides to do so, it has to report profits in this country in order to be able to absorb foreign losses. However, as a positive $\sigma$ discourages investment, it is mostly through profit shifting that companies would benefit, were they to decide to move their headquarter. The government, on the other hand, benefits from the profit shifting, which occurs.

Therefore, the current analysis has shown that cross-border loss-offset is a tax competition instrument, which is only used when a country tries to attract mobile profits. Furthermore, Proposition 2 shows that the welfare of each country in a noncooperative Nash equilibrium may be an increasing function of the easiness of implementing international tax planning. This is the case, if its impact on the inefficiency of the corporate tax does not reduce welfare by more than its impact on the loss compensation rule increases welfare.

However, the model is too complex to derive analytical results on the impact of international profit shifting on equilibrium welfare. Therefore, we perform numerical analysis of the model for different parameter values to illustrate the results.

\section{Simulation}

We simulate our results under the assumption of a quadratic production function, i.e. $f\left(k_{i}^{j}\right)=(a-$ $\left.(b / 2) k_{i}^{j}\right) k_{i}^{j}, \forall i, j, a, b>0$. The results of the simulation are given in Table 1 .

\begin{tabular}{|l|c|ccccccc|}
\hline & $c$ & $U_{i}$ & $t_{i}$ & $\sigma_{i}$ & $k_{i}^{i}$ & $k_{i}^{j}$ & $s_{i}^{i}$ & $s_{i}^{j}$ \\
\hline Social Planner & $\in] 0, \infty[$ & 8.75 & $\in[0,1[$ & 1 & 1 & 1 & 0 & 0 \\
No Profit Shifting & $\infty$ & 8.741 & 0.323 & 0 & 1.168 & 0.958 & 0 & 0 \\
Low Profit Shifting & 0.1 & 8.724 & 0.186 & 0.159 & 1.079 & 0.98 & 0.625 & -0.16 \\
Intermediate Profit Shifting & 0.05 & 8.742 & 0.134 & 0.539 & 1.031 & 0.992 & 0.496 & -0.124 \\
High Profit Shifting & 0.01 & 8.749 & 0.041 & 0.884 & 1.002 & 0.999 & 0.187 & -0.047 \\
\hline
\end{tabular}

Table 1: Numerical solution of the model for $\bar{k}_{i}=5, n=5, a=2, b=0.5, \rho=0.4, p=0.5$.

The benchmark parameter values are $\bar{k}_{i}=5, n=5, a=2, b=0.5, \rho=0.4, p=0.5$. Thus, there is $50 \%$ chance that investment in the foreign country will be successful (and bring twice the domestic revenues) and $50 \%$ probability of zero sales. The parameter value $\rho=0.4$ corresponds to deductibility of $40 \%$ of capital costs, i.e. if there is no depreciation, it implies $40 \%$ debt-to-capital ratio. Lastly, $\bar{k}_{i}=n=5$ means that in a symmetric situation with full loss-offset, the representative MNE invests 1 unit of capital in each subsidiary.

Table 1 considers five different cases. The first case is of a social planner and gives the maximum attainable utility for any degree of profit shifting possibilities. In equilibrium $s_{i}^{j}=0$, due to the symmetry of the tax treatment of home and foreign losses (i.e. $\hat{\sigma}=1$ ). Moreover, there is production efficiency, i.e. 
each MNE invests equal amounts in its home and foreign subsidiaries 15

In the second row of Table 1 we consider the case of capital mobility, but no profit shifting opportunities, i.e. $c \rightarrow \infty$. In this case the equilibrium loss-offset becomes zero, while the equilibrium tax rate is $t^{*}=0.323$. This leads to higher investment in the home subsidiary relative to the first-best case $\left(k_{i}^{i}\right.$ increases from 1 to 1.168) and less foreign investment undertaken by each MNE ( $k_{i}^{j}$ declines from 1 to 0.958$)$. This results in production inefficiency and leads to lower equilibrium utility $U^{*}=8.741<\hat{U}=8.75$

The last three rows analyze the noncooperative equilibrium, when profit shifting possibilities exist. First, when the marginal concealment costs are relatively large $(c=0.1)$, the optimal cross-border lossoffset is 0.159 . The equilibrium tax falls to 0.186 . The production inefficiency declines as capital in the home subsidiary is 1.079 , which is less than in the case of capital mobility (1.168), but still above the first-best level of 1 . There is also profit shifting in equilibrium from the home to foreign subsidiaries $\left(\tilde{s}_{i}^{i}=0.625, \tilde{s}_{i}^{j}=-0.16\right)$, because of the incomplete loss-compensation. As a result, equilibrium utility drops further, i.e. $\tilde{U}(c=0.1)=8.724<U^{*}<\hat{U}$.

However, as the marginal costs of profit shifting drop, $\tilde{\sigma}$ rises. If $c=0.05$, the optimal loss relief becomes 0.539 and the equilibrium tax rate goes down to 0.134 . Utility in equilibrium rises with lower concealment costs, because of the relaxation of loss compensation, to $\tilde{U}(c=0.05)=8.742>\tilde{U}(c=0.1)$. Moreover, welfare in this case (with profit shifting) is higher than in the absence of profit shifting $(8.742>$ 8.741). This happens because the production inefficiency in mitigated and in spite of the profit shifting in equilibrium. Furthermore, as the marginal concealment costs of profit shifting decline, the equilibrium $s_{i}^{i}$ and $s_{i}^{j}$ decrease in absolute value (see the last two columns of Table 1). The reason is that lower $c$ raises the equilibrium loss-offset, which exerts a negative impact on the incentives to transfer profits.

Lastly, reducing further the marginal concealment costs raises the equilibrium loss-offset and lowers the equilibrium tax rate. Both effects lower the incentives of multinationals to invest more at home than in the foreign subsidiary and to shift profits. The impact on welfare is positive.

Hence, the simulation has shown that introducing profit shifting possibilities may be welfareimproving in this model. The less costly it is for each multinational to minimize its worldwide tax liabilities, the larger is the negative profit fiscal externality. Since it moves the decentralized equilibrium loss-relief to its first-best level, utility of the resident of each country may rise.

This result is essential to the discussion of profit shifting activities of MNEs, which usually focuses on their negative welfare implications. To the best of our knowledge, the only other article which derives a positive impact of international tax planning on utility is Hong and Smart (2010). They show that real investment of MNEs is less sensitive to tax rate hikes, if they are able to report profits in tax havens. This allows governments in high-tax countries to increase the equilibrium tax rates above their level in the absence of international tax planning. As a result, tax competition is mitigated and welfare rises.

Our analysis complements this article by deriving a new positive feature of profit shifting. It mitigates the incentives of governments to favor home investment against foreign investment in their tax

\footnotetext{
${ }^{15}$ The equilibrium interest rate is not reported in Table 1 It depends on the tax rate and equals $r=7.5(1-t) /(5-t)$.

${ }^{16}$ The interest rate is in this case determined and equals $r=1.1$.
} 
codes. Since this discrimination leads to production inefficiency, the introduction of tax planning may be welfare-improving.

\section{Discussion and Extensions}

The European Commission (2006a) views the introduction of cross-border loss-offset as an intermediate solution towards the implementation of a Common Consolidated Corporate Tax Base (CCCTB). It has advocated this view on several grounds. First, in the absence of loss-relief domestic investments are favored against investments in other member states. Second, large member states are more attractive investment locations, because of their larger markets and, thus, less risk that losses cannot be set off against potential profits. Moreover, large companies are favored against small and medium-sized enterprises, because they are able to invest in more activities abroad and, therefore, absorb losses from one activity with profits from another activity in the same country. Additionally, the choice between a permanent establishment and a subsidiary is influenced, because currently losses of permanent establishments are transferrable across borders.

Even though the Commission considers three different approaches for loss-relief, the approach which is favored by the European Parliament is the "deduction/reintegration method" (temporary loss transfer) European Parliament, 2008 ${ }^{17}$ It allows a parent company to deduct from its revenue losses from a foreign subsidiary. However, in order to avoid a double use of foreign losses, the cross-border loss-relief is recaptured when the foreign subsidiary becomes profitable (and can use a carry-forward abroad). Thus, this method avoids a double use of losse: 18

The current analysis has derived analytical results, which support the joint implementation of crossborder loss-offset in the European Union. However, there are two further issues, which have not been addressed by the analysis so far. First, we have ignored the possibility that the public good may have larger weight in the welfare function than private consumption. If this holds, the first-best level of $\sigma$ falls below $100 \%$. Nevertheless, the main results of the paper remain qualitatively unchanged, i.e. joint coordination of the loss-relief remains in general welfare-improving. Second, we have neglected the impact of cross-border loss-relief on the riskiness of government revenues. If governments are interested in minimizing the variation of tax receipts, less than full loss-offset may be optimal. In the following, we will illustrate these two extensions.

\footnotetext{
${ }^{17}$ The other two approaches are "intra-group loss transfer" and "system of consolidated profits". Under the first one, there is a definitive transfer of losses or profits without recapture, which may create problems of double use of losses. The other approach consolidates profits and losses of some or all group members at the level of the parent company and would eliminate the possibility of double taxation and double use of losses by applying the credit method. However, it would lead to large compliance costs (European Commission 2006a).

${ }^{18}$ This is also the method analyzed in this paper, even though we did not model the recapture of foreign losses. However, introducing a recapture in a second period does not change qualitatively the results of the model.
} 
Assume first that the public good has a weight $\lambda>1$ in the utility function, such that 19

$$
E\left(U_{i}\right)=E\left(x_{i}+\lambda g_{i}\right)
$$

In this case a social planner must weight the benefits of increasing $\sigma$ against the loss of tax revenue, which has larger weight than private consumption. Therefore, the first-best level of the loss-relief is between zero and one (the equilibrium values of the loss-offset provisions $\hat{\sigma}, \sigma^{*}$ and $\tilde{\sigma}$ when utility is represented by (28) are derived in Appendix C). However, the externalities which $\sigma_{i}$ imposes on countries $j$ remain qualitatively unchanged. Thus, when only capital relocates, the noncooperative loss-offset is zero and remains inefficiently low. On the other hand, under capital and profit mobility, each government sets $\sigma_{i}$ at a positive level. Since $\hat{\sigma}<1$, the optimal decentralized loss compensation may be inefficiently high in the case of a sufficiently strong profit fiscal externality. However, if the marginal concealment costs are not too negligible, the decentralized loss-relief remains inefficiently low as in the main setting of the model. As a consequence, the results are likely to be preserved, if one uses as welfare function (28) instead of 12 .

Another implication of the loss-relief mechanism is that it affects the volatility of public revenues. This effect is important, because governments may wish to minimize the uncertainty of tax receipts. An example of such policy is the minimum taxation in Germany, which limits the use of loss carryforwards up to $60 \%$ of corporate income in excess of one million Euro. Therefore, we need to derive the impact of the cross-border loss-offset on the variance of $g_{i}$, which is given by

$$
\operatorname{Var}\left(g_{i}\right)=p(1-p) t_{i}^{2}\left[\sigma_{i}^{2}\left(\sum_{j \neq i}\left(\rho r k_{i}^{j}+s_{i}^{j}\right)\right)^{2}+\left(\sum_{j \neq i}\left(\frac{1}{p} f\left(k_{j}^{i}\right)-\rho r k_{j}^{i}-s_{j}^{i}\right)\right)^{2}\right] .
$$

Equation 29] shows that the direct effect of $\sigma_{i}$ on the variance of tax revenues is positive. This impact mitigates the social planner's and regional governments' incentives to relax the loss-offset provisions. Nevertheless, the overall effect of $\sigma_{i}$ on the variance is unknown. Moreover, we can show that a marginal introduction of a loss-offset rule above zero actually reduces the variability of $g_{i}$. The marginal impact is derived by taking the derivative of $\operatorname{Var}\left(g_{i}\right)$ with respect to $\sigma_{i}$ and estimating it at a symmetric situation with $\sigma_{i}=\sigma_{j}=0$ :

$$
\left.\frac{\partial \operatorname{Var}\left(g_{i}\right)}{\partial \sigma_{i}}\right|_{\sigma=0}=2 p(1-p) t_{i}^{2}(n-1)\left(\frac{1}{p} f\left(k_{j}^{i}\right)-\rho r k_{j}^{i}-s_{j}^{i}\right)\left[(n-1)\left(\frac{1}{p} f^{\prime}\left(k_{j}^{i}\right)-\rho r\right) \frac{\partial k_{j}^{i}}{\partial \sigma_{i}}-\rho k_{j}^{i} \frac{\partial r}{\partial \sigma_{i}}\right]<0 .
$$

The above result is based on the negative effect of the loss relief on the inward foreign direct investment $k_{j}^{i}$ and its positive impact on the interest rate $r$. However, relaxing further $\sigma$ raises the variance of $g_{i}$

\footnotetext{
${ }^{19}$ The objective function in 28 is standard in the literature (see e.g. Bucovetsky and Haufler 2008); Haufler and Runkel (2012)). One way to interpret it is to assume that the public good has a constant marginal valuation above its cost. Another possible explanation would be that there is some other distortionary tax with marginal excess burden of $\lambda-1>0$. Keeping the government revenue constant, higher corporate taxation allows a reduction of the other tax rate and the distortion associated with it.
} 
both through the increased proportion of foreign-incurred losses $\left(\rho r k_{i}^{j}+s_{i}^{j}\right)$ which are transferable across borders and through its positive effect on these losses, given by $d\left(\rho r k_{i}^{j}+s_{i}^{j}\right) / d \sigma_{i}>0$. The net impact of the loss relief on the variance is undetermined for positive values of $\sigma_{i}$.

Nevertheless, the above result shows that even if a government is interested in minimizing the variability of its revenues, a positive degree of cross-border loss-relief may be optimal. However, further research is necessary in order to establish the exact relationship between the loss-offset provisions and the uncertainty of tax revenues.

\section{Conclusions}

This article has analyzed cross-border loss-offset as a tax competition instrument. If countries compete only to attract physical investment, they will never introduce a cross-border loss-relief, because it stimulates MNEs to invest abroad (exerting a positive externality on the rest of the world). If countries compete to attract mobile capital and profits, in contrast, they will relax the degree of loss compensation, because it stimulates the MNEs to transfer profits to their parent (exerting a negative externality on the remaining countries). However, the equilibrium loss-relief remains inefficiently low and a joint coordination is welfare-improving.

Thus, unlike the corporate tax rate, which affects negatively both domestic investment and the reported tax base and is ubiquitously used as a tax competition device, the cross-border loss-offset will be put in place only by those countries, which face more mobile profits than investment.

These results are in line with empirical evidence. Reductions of the corporate tax rate during the last decades are widely documented, e.g. Devereux et al. (2008) observe a decrease of the mean statutory rate in 21 OECD countries from $46.5 \%$ in 1982 to $34.7 \%$ in 1999. However, cross-border loss-offset is rarely implemented. There are only four countries in the EU, which have introduced it: Denmark, France, Italy and Austria.

We find that joint introduction of full cross-border loss-offset is welfare-improving, because it ensures production efficiency and zero profit shifting in equilibrium. However, it may raise new problems to governments such as increased volatility of public revenues. Further analysis is necessary to determine how governments can react to these issues.

\section{A Solving the Maximization Problem of MNEs}

$\mathrm{MNE}_{i}$ solves the maximization problem described by Equation (4). Its Lagrange function is given by

$$
\begin{aligned}
L= & f\left(k_{i}^{i}\right)\left(1-t_{i}\right)+t_{i}\left(\rho r k_{i}^{i}+s_{i}^{i}\right)+t_{i} \sigma_{i} \sum_{j \neq i}\left[\rho r k_{i}^{j}+s_{i}^{j}\right](1-p) \\
& +\sum_{j \neq i}\left[f\left(k_{i}^{j}\right)\left(1-t_{j}\right)+t_{j} p\left(\rho r k_{i}^{j}+s_{i}^{j}\right)\right]-r k_{i}-C-\lambda \sum_{j=1}^{n} s_{i}^{j},
\end{aligned}
$$


where $\lambda$ denotes the Lagrange multiplier. Its first-order conditions are

$$
\begin{aligned}
& \frac{\partial L}{\partial k_{i}^{i}}=f^{\prime}\left(k_{i}^{i}\right)\left(1-t_{i}\right)+t_{i} \rho r-r=0, \\
& \frac{\partial L}{\partial k_{i}^{j}}=f^{\prime}\left(k_{i}^{j}\right)\left(1-t_{j}\right)+t_{j} \rho r p+t_{i} \sigma_{i} \rho r(1-p)-r=0, \quad \forall j \neq i, \\
& \frac{\partial L}{\partial s_{i}^{i}}=t_{i}-c s_{i}^{i}-\lambda=0, \\
& \frac{\partial L}{\partial s_{i}^{j}}=p t_{j}+t_{i} \sigma_{i}(1-p)-c s_{i}^{j}-\lambda=0, \quad \forall j \neq i, \\
& \frac{\partial L}{\partial \lambda}=-\sum_{j=1}^{n} s_{i}^{j}=0 .
\end{aligned}
$$

Solving Equations (A.31a and A.31b gives Equations (5a) and (5b) in the main text. The solutions of A.31c and A.31d give

$$
\begin{aligned}
s_{i}^{i} & =\frac{t_{i}-\lambda}{c}, \\
s_{i}^{j} & =\frac{p t_{j}+t_{i} \sigma_{i}(1-p)-\lambda}{c}, \quad \forall j \neq i .
\end{aligned}
$$

Summing A.32 and A.33 and plugging A.31e in the resulting equation, we can solve for $\lambda: \lambda=$ $\left[t_{i}\left(1+(n-1) \sigma_{i}(1-p)\right)+p \sum_{j \neq i} t_{j}\right] / n$. Plugging the optimal value of $\lambda$ in A.32 and A.33 gives Equations (5c) and (5d) in the main text.

\section{B Derivation of the Comparative Statics Results (6)-(7)}

In order to derive the comparative static effects of changes in $t_{i}$ and $\sigma_{i}$ on the optimal investment levels, we need to totally differentiate the system of Equations (5a)-(5b) and the capital market clearing condition $\sum_{i} \sum_{j} k_{i}^{j}=\sum_{i} \bar{k}_{i}$ with respect to $t_{i}, \sigma_{i}$ and $k_{i}^{j}, \forall i, j$. In doing so, we obtain the following $n^{2}+1$ equations:

$$
\begin{aligned}
-b d k_{i}^{i} & =\frac{\left(1-\rho t_{i}\right)}{\left(1-t_{i}\right)} d r+\frac{(1-\rho) r}{\left(1-t_{i}\right)^{2}} d t_{i}+0 d \sigma_{i}, \\
-b d k_{i}^{j} & =\frac{\left(1-\rho\left(t_{j} p+t_{i} \sigma_{i}(1-p)\right)\right)}{\left(1-t_{j}\right)} d r-\frac{\rho \sigma_{i}(1-p) r}{\left(1-t_{j}\right)} d t_{i}-\frac{\rho t_{i}(1-p) r}{\left(1-t_{j}\right)} d \sigma_{i}, \forall j \neq i, \\
-b d k_{j}^{j} & =\frac{\left(1-\rho t_{j}\right)}{\left(1-t_{j}\right)} d r+0 d t_{i}+0 d \sigma_{i}, \quad \forall j \neq i, \\
-b d k_{j}^{l} & =\frac{\left(1-\rho\left(t_{l} p+t_{j} \sigma_{j}(1-p)\right)\right)}{\left(1-t_{l}\right)} d r+0 d t_{i}+0 d \sigma_{i}, \quad \forall j \neq i, l, \forall l \neq i, j, \\
-b d k_{j}^{i} & =\frac{\left(1-\rho\left(t_{i} p+t_{j} \sigma_{j}(1-p)\right)\right)}{\left(1-t_{i}\right)} d r+\frac{\left(1-\rho\left(p+t_{j} \sigma_{j}(1-p)\right)\right) r}{\left(1-t_{i}\right)^{2}} d t_{i}+0 d \sigma_{i}, \forall j \neq i, \\
0 & =\sum_{i=1}^{n} \sum_{j=1}^{n} k_{i}^{j} .
\end{aligned}
$$

First, we set $d \sigma_{i}=0$ and solve for $d t_{i} \neq 0$. Summing Equations (B.34)-(B.38) and plugging in (B.39), we can derive the impact of a tax rate change on the interest rate ( $6 \mathrm{aa})$ in the main text). Evaluating in 
a symmetric situation, we get

$$
\frac{\partial r}{\partial t_{i}}=-\frac{r(1-\rho+(n-1)(1-\rho(p+\sigma(1-p))))}{n(1-t)[(1-\rho t)+(n-1)(1-\rho t(p+\sigma(1-p)))]}<0,
$$

Moreover, we can use the first-order conditions (5a) and (5b) in order to simplify (B.40). Rearranging (5a) and (5b), we get

$$
f^{\prime}\left(k_{i}^{i}\right)-\rho r=\frac{(1-\rho) r}{(1-t)}, \quad f^{\prime}\left(k_{i}^{j}\right)-\rho r(p+\sigma(1-p))=\frac{(1-\rho(p+\sigma(1-p))) r}{(1-t)} .
$$

Plugging (B.41) in (B.40) gives Equation 6a in the main text. Furthermore, from combining (6a) with (B.35, (B.36) and (B.37) follow immediately Equations (6c), 6d and 6e). In order to derive (6b), we need to plug (6a) in B.34 and evaluate at a symmetric situation:

$$
\begin{aligned}
\frac{\partial k_{i}^{i}}{\partial t_{i}} & =\frac{\left(1-\rho t_{i}\right)}{b\left(1-t_{i}\right)} \frac{\left(f^{\prime}\left(k_{i}^{i}\right)-\rho r\right)+(n-1)\left(f^{\prime}\left(k_{i}^{j}\right)-\rho r(p+\sigma(1-p))\right)}{n[(1-\rho t)+(n-1)(1-\rho t(p+\sigma(1-p)))]}-\frac{\left(f^{\prime}\left(k_{i}^{i}\right)-\rho r\right)}{b(1-t)} \\
& =\frac{\left.(1-\rho t)\left(f^{\prime}\left(k_{i}^{j}\right)-\rho r(p+\sigma(1-p))\right)\right]-(n-1)\left[\left(f^{\prime}\left(k_{i}^{i}\right)-\rho r\right)(1-\rho t+n(1-\rho t(p+\sigma(1-p))))\right.}{b(1-t) n[(1-\rho t)+(n-1)(1-\rho t(p+\sigma(1-p)))]} \\
& =-\frac{(n-1)\left[n\left(f^{\prime}\left(k_{i}^{i}\right)-\rho r\right)(1-\rho t(p+\sigma(1-p)))-(1-\rho t) \rho r(1-p)(1-\sigma) /(1-t)\right]}{b(1-t) n[(1-\rho t)+(n-1)(1-\rho t(p+\sigma(1-p)))]}, \quad \text { (B.42) }
\end{aligned}
$$

where in the last equality we used $f^{\prime}\left(k_{i}^{i}\right)-\rho r-\left(f^{\prime}\left(k_{i}^{j}\right)-\rho r(p+\sigma(1-p))\right)=-\rho r(1-p)(1-\sigma) /(1-t)$. Finally, we can replace $\left(f^{\prime}\left(k_{i}^{i}\right)-\rho r\right)(1-\rho t(p+\sigma(1-p)))$ by $(1-\rho) f^{\prime}\left(k_{i}^{j}\right)$ and $(1-\rho t) r /(1-t)$ by $f^{\prime}\left(k_{i}^{i}\right)$ in the last row of Equation $(\mathrm{B} .42)$ in order to derive $(6 \mathrm{~b})$ in the main text.

Furthermore, (6f) can be derived by plugging (B.40) in (B.38), evaluating in a symmetric situation and simplifying:

$$
\begin{aligned}
\frac{\partial k_{j}^{i}}{\partial t_{i}}= & -\frac{(1-\rho t(p+\sigma(1-p)))}{b(1-t)} \frac{\partial r}{\partial t_{i}}-\frac{(1-\rho(p+t \sigma(1-p))) r}{b(1-t)^{2}} \\
= & -\frac{\left[\begin{array}{c}
(1-\rho(p+t \sigma(1-p))) n[1-\rho t+(n-1)(1-\rho t(p+\sigma(1-p)))] \\
-(1-\rho t(p+\sigma(1-p)))[1-\rho+(n-1)(1-\rho(p+\sigma(1-p)))]
\end{array}\right] r}{b(1-t)^{2} n[(1-\rho t)+(n-1)(1-\rho t(p+\sigma(1-p)))]} .
\end{aligned}
$$

The denominator of $(\mathrm{B} .43)$ coincides with the denominator of $(6 \mathrm{ft})$, while the numerator can be shown to equal $\Gamma>0$ after some tedious calculations.

The second step is to derive the comparative statics results when the loss-offset rule changes. Setting $d \sigma_{i} \neq 0$ and $d t_{i}=0$ in Equations B.34-B.38 and summing up all equations, we can show that in symmetric situation

$$
\frac{\partial r}{\partial \sigma_{i}}=\frac{r \rho t(1-p)(n-1)}{n[(1-\rho t)+(n-1)(1-\rho t(p+\sigma(1-p)))]}>0 .
$$

Equation (B.44) coincides with $(7 \mathrm{a})$ in the main text. Furthermore, plugging (B.44) in (B.34)-(B.38), one can immediately derive Equations $7 \mathrm{bb}-(7 \mathrm{~d})$. 


\section{Derivation of the Equilibrium Loss-Offset When Utility is Represented by (28)}

If the utility function is given by (28), then the first-order condition of the social planner with respect to $\sigma_{i}$ is given by

$$
\begin{aligned}
& \frac{\partial E(U)}{\partial \sigma_{i}}=t_{i} \sum_{j \neq i}\left(\rho r k_{i}^{j}+s_{i}^{j}\right)(1-p)(1-\lambda)+\sum_{j=1}^{n} \frac{\partial E\left(U_{j}\right)}{\partial r} \frac{\partial r}{\partial \sigma_{i}} \\
&+\lambda \sum_{j=1}^{n} t_{j}\left[\left(f^{\prime}\left(k_{j}^{j}\right)-\rho r\right) \frac{\partial k_{j}^{j}}{\partial \sigma_{i}}+\sum_{i \neq j}\left(\left(f^{\prime}\left(k_{i}^{j}\right)-p \rho r\right) \frac{\partial k_{i}^{j}}{\partial \sigma_{i}}-\sigma_{j} \rho r(1-p) \frac{\partial k_{j}^{i}}{\partial \sigma_{i}}\right)\right] \\
&-\lambda t_{i} \frac{\partial s_{i}^{i}}{\partial \sigma_{i}}-\lambda \sum_{\substack{j=1 \\
j \neq i}}^{n}\left[t_{j} p+t_{i} \sigma_{i}(1-p)\right] \frac{\partial s_{i}^{j}}{\partial \sigma_{i}}=0,
\end{aligned}
$$

where

$$
\begin{aligned}
\frac{\partial E\left(U_{j}\right)}{\partial r}= & \left(\bar{k}_{j}-\frac{1}{n} \sum_{i=1}^{n} k_{i}\right)+\frac{1}{n} \sum_{i=1}^{n}\left[t_{i} \rho k_{i}^{i}+\sum_{l \neq i} \rho k_{i}^{l}\left(t_{i} \sigma_{i}(1-p)+t_{l} p\right)\right] \\
& -\lambda\left[t_{j} \rho k_{j}^{j}+\sum_{i \neq j}\left(t_{j} \sigma_{j} \rho k_{j}^{i}(1-p)+t_{j} \rho \rho k_{i}^{j}\right)\right] .
\end{aligned}
$$

Equation C.45 differs from the social planner's first-order condition when $\lambda=1$ by the first two terms, which are negative. First, higher $\sigma_{i}$ reduces public good provision in country $i$ by the same amount by which it increases private income. However, the net direct effect is negative due to the higher weight of $g_{i}$ in the utility function. Second, the positive impact of $\sigma_{i}$ on $r$ also decreases welfare of all countries, because an increase in the interest rate lowers tax revenues (according to the second row of (C.46) by the same amount by which it decreases the tax payments of MNEs. Due to $\lambda>1$, the net effect is negative. However, the second and third row of C.45 are positive and lead to $\hat{\sigma}$ which is between zero and one when there is an interior solution.

The first-order condition with respect to $\sigma_{i}$ of national governments is given by

$$
\begin{aligned}
\frac{\partial E\left(U_{i}\right)}{\partial \sigma_{i}}=t_{i} \sum_{j \neq i} & \left(\rho r k_{i}^{j}+s_{i}^{j}\right)(1-p)\left(\frac{1}{n}-\lambda\right)+\frac{\partial E\left(U_{i}\right)}{\partial r} \frac{\partial r}{\sigma_{i}}-\lambda t_{i}\left(1-\sigma_{i}(1-p)\right) \frac{\partial s_{i}^{i}}{\partial \sigma_{i}} \\
+\lambda t_{i} & {\left[\left(f^{\prime}\left(k_{i}^{i}\right)-\rho r\right) \frac{\partial k_{i}^{i}}{\partial \sigma_{i}}+\sum_{j \neq i}\left(\left(f^{\prime}\left(k_{j}^{i}\right)-p \rho r\right) \frac{\partial k_{j}^{i}}{\partial \sigma_{i}}-\sigma_{i} \rho r(1-p) \frac{\partial k_{i}^{j}}{\partial \sigma_{i}}\right)\right]=0 . }
\end{aligned}
$$

The above equation is negative for all values of $\sigma_{i}$ when there is no profit shifting, i.e. when $c \rightarrow$ $\infty$. Compared to 18 in the main text, the negative terms are more pronounced due to $\lambda>1$ and an additional negative term through the interest rate change appears, i.e. $\left(\partial E\left(U_{i}\right) / \partial r\right)\left(\partial r / \partial \sigma_{i}\right)<0$ according to C.46. Therefore, $\sigma^{*}=0$ as in the main text with $\lambda=1$. Introducing profit shifting creates a negative externality of the cross-border loss-offset, which may lead to a positive equilibrium loss-relief. 
However, if the marginal costs of profit shifting are too low, i.e. if $c \rightarrow 0$, the last term on the first row of (C.47) may be large enough to induce inefficiently high loss-offset.

\section{References}

Altshuler, R. and Auerbach, A. J. (1990). The significance of tax law asymmetries: An empirical investigation. The Quarterly Journal of Economics, 105(1):61-86.

Auerbach, A. J. (1986). The dynamic effects of tax law asymmetries. Review of Economic Studies, $53(2): 205-25$.

Bucovetsky, S. and Haufler, A. (2008). Tax competition when firms choose their organizational form: Should tax loopholes for multinationals be closed. Journal of International Economics, 74(1):188-201.

Creedy, J. and Gemmell, N. (2011). Corporation tax asymmetries: effective tax rates and profit shifting. International Tax and Public Finance, 18(4):422-435.

Devereux, M. P. (1989). Tax asymmetries, the cost of capital and investment: some evidence from United Kingdom panel data. The Economic Journal, 99(395):103-112.

Devereux, M. P., Lockwood, B., and Redoano, M. (2008). Do countries compete over corporate tax rates? Journal of Public Economics, 92(5-6):1210-1235.

Edgerton, J. (2010). Investment incentives and corporate tax asymmetries. Journal of Public Economics, 94(11-12):936-952.

European Commission (2006a). Tax Treatment of Losses in Cross-Border Situations, COM(2006) 824 Final.

European Commission (2006b). Tax Treatment of Losses in Cross-Border Situations, Technical Annexes, $\operatorname{COM}(2006) 824$ Final.

European Parliament (2008). European Parliament resolution of 15 January 2008 on tax treatment of losses in cross-border situations (2007/2144(INI)). Official Journal of the European Union.

Gérard, M. (2005). Multijurisdictional firms and governments' strategies under alternative tax designs. CESifo Working Paper Series 1527, CESifo Group Munich.

Gérard, M. and Weiner, J. (2003). Cross-border loss offset and formulary apportionment: How do they affect multijurisdictional firm investment spending and interjurisdictional tax competition ? CESifo Working Paper Series 1004, CESifo Group Munich.

Haufler, A. and Mardan, M. (2014). Cross-border loss offset can fuel tax competition. Journal of Economic Behavior \& Organization, 106(C):42-61. 
Haufler, A. and Runkel, M. (2012). Firms' financial choices and thin capitalization rules under corporate tax competition. European Economic Review, 56(6):1087-1103.

Haufler, A. and Schjelderup, G. (2000). Corporate tax systems and cross country profit shifting. Oxford Economic Papers, 52(2):306-25.

Hong, Q. and Smart, M. (2010). In praise of tax havens: International tax planning and foreign direct investment. European Economic Review, 54(1):82-95.

Lee, K. (2004). Taxation of mobile factors as insurance under uncertainty. Scandinavian Journal of Economics, 106(2):253-271.

Mayer, C. (1986). Corporation tax, finance and the cost of capital. Review of Economic Studies, 53(1):93112.

Niemann, R. and Treisch, C. (2005). Group taxation, asymmetric taxation and cross-border investment incentives in austria. CESifo Working Paper No. 1506, CESifo Group Munich.

Panteghini, P. M. (2001a). Corporate tax asymmetries under investment irreversibility. FinanzArchiv: Public Finance Analysis, 58(3):207-.

Panteghini, P. M. (2001b). On corporate tax asymmetries and neutrality. German Economic Review, $2(3): 269-286$.

Wildasin, D. E. and Wilson, J. D. (1998). Risky local tax bases: risk-pooling vs. rent-capture. Journal of Public Economics, 69:229-247. 